\title{
Homocysteine and arteriosclerosis
}

SIR - Spurred on by a recent book', I would like to remind Nature's readers that the cholesterol theory is not the only one that could explain arteriosclerosis; the homocysteine theory has been developing since the 1960s as the result of studying youngsters with a disease known as homocystinurea. Victims of homocystinurea usually die of vascular complications between the ages of 7 and 13, but in some cases the high homocysteine levels are responsive to vitamin $B_{6}$ therapy and some people with homocystinurea are now saved.

An insufficient amount of vitamin $\mathbf{B}_{6}$ will result in contact inhibition causing smooth cells to grow abnormally ${ }^{2,3}$. The connection lies in the consumption of the amino acid methionine, which is ultimately metabolized to homocysteine. Vitamin $\mathbf{B}_{6}$ is required for the further metabolism of homocysteine, and if this transformation is inhibited, homocysteine can build up. Homocysteine causes smooth cells to grow abnormally. Since areas of abnormal smooth cell growth in arterial endothelial lining may become sites of cholesterol plaque formation, cholesterol and other lipid accumulation may then be a direct consequence of the abnormal smooth cell growth. Many people generally consider that there is (or must be) enough vitamin $B_{6}$ in their diet. However, in 1955 Henry Schroeder found that in the United States the foods in the typical diet have low levels of vitamin $\mathrm{B}_{6}$ due to processing and cooking, and that the diet contains an insufficient amount of $\mathbf{B}_{6}$ during most of the year ${ }^{4}$.

As eloquently presented in a review article by H.C. McGill Jr, there exists no correlation between dietary cholesterol and serum levels of cholesterol ${ }^{5}$. Interestingly, serum cholesterol can be modulated by sucrose (able sugar). In 1964 Winitz et al. reported that as sucrose was increased from 0 to $25 \%$ of the total carbohydrate source in a defined diet of normal adults, their serum cholesterol levels increased concomitantly from 160 to $208 \mathrm{mg}$ per cent. Subsequently, when the diets were changed to $100 \%$ glucose carbohydrate source (sucrose free) for an eighteen-week period, the average serum cholesterol level fell to 151 mg per cent ${ }^{6.7}$.

This raises three questions. (1) Would it be appropriate to focus more attention on the alternate theory of arteriosclerosis, namely, the homocysteine theory (the lack of vitamin $B_{6}$ )? (2) Why is sucrose never discussed or alluded to as a potential problem associated with raised cholesterol levels (sucrose being one of the few commodities that we ingest in large amounts daily)? (3) Very few of my colleagues or friends take vitamins; in this society where a lot of our food is cooked fast, well done, and with lots of protein, should we be more concerned with taking some vitamins daily? We must make sure that the role essential vitamins play in our health is not overlooked because of recent controversy over megavitamin therapies.

There is a danger that this most interesting theory (the homocysteine theory) and the sucrose involvement may be overlooked. If these concepts are as important to every one of us as they seem, it would be a shame for them to go unnoticed one minute longer.

\section{Veterinary Toxicology and}

Research Laboratory,

Agricultural Research Service,

US Department of Agriculture,

College Station, Texas 77841, USA

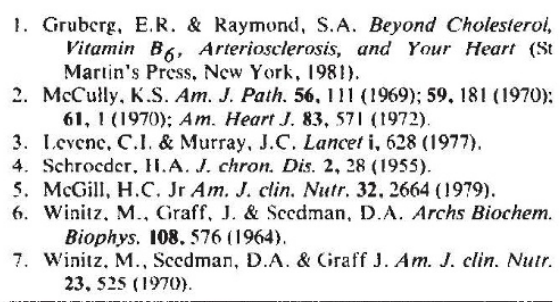

\section{Fungi in culture}

SIR - During work in connection with the UK National Collection of Fungus Cultures, it has emerged that too many authors of papers which use fungus cultures do not (1) have the identity of the material checked by a specialist, and/or (2) deposit a sub-culture in a national collection where it can be preserved and so made available to later workers (or even the same worker if his cultures die or become contaminated). Too much elegant biochemical and chemical work in genera such as Penicillium and Trichoderma is already unusable because of uncertainties over the identity of material studied for which isolates were not preserved in a public collection. The UK National Collection of Fungus Cultures, held at this institute since 1947 , already holds about 11,000 strains in pure culture, by a wide variety of methods (depending on the fungi concerned). [See The Preservation and Maintenance of Living Fungi, Commonwealth Mycological Institute, $£ 6.50$ post free.]

Isolates to be cited in publications are normally accepted for deposit free of charge, and can be preserved and held in confidence in advance of publication. The institute is also an international depositary for patent strains and operates a safedeposit service.

Where fungi have not been checked by an expert, the institute staff of about 70 includes 16 specialist taxonomists who provide a world identification service. This service is free for non-commercial UK submissions.

\section{Culture Collection \& Industrial Services,} Commonwealth Mycological Institute, Ferry Lane,

Kew, Surrey TW9 $3 A F, U K$

\section{Oil-shale petroporphyrin}

SIR - I was interested to learn that Ekstrom et al. determined the X-ray structure of the naturally occurring petroporphyrin, vanadyl deoxophyllerythroetioporphyrin (VODPEP) (Nature 306, 173; 1983). The authors did not mention, but I would like to add, that the X-ray structure of synthetic VO-DPEP was published in 1968 and $1969^{1,2}$. From the structure diagrams of Ekstrom, the synthetic and natural VODPEP are identical. The crystal structures are not identical because 1,2-dichloroethane is present as solvent of crystallization in synthetic VO-DPEP. Ekstrom's unit cell packing diagram looks as if that structure contains chloroform as a solvent of crystallization. This is logical because the unit cell volumes are very similar (synthetic: $3,149 \AA^{3}$; natural: $3,167 \AA^{3}$ ).

ROGER C. PETTERSEN

Forest Products Laboratory,

US Department of Agriculture,

PO Box 5130, Madison,

Wisconsin 53705, USA

1. Pettersen, R.C. \& Alexander, L.E. J, Am, chem, Soc. 90 3873-5 (1984).

2. Petterson, R.C. Acta crystallogr. B25, 2527-39 (1969).

\section{Canary before the pigeon}

SIR - Epstein et al. ${ }^{1}$ recently reported the replication of W. Köhler's one-box problem but with the bird (pigeon) as the subject instead of the chimpanzee, as was the case in Köhler's experiments. But Epstein et al. overlooked the relevant literature with the bird as the subject. About thirty years ago, I undertook the replication of Köhler's one-box problem as well as the replication of Köhler's stacking problem (that is, stacking two, three or four boxes) with the bird as the subject (canary). Of course Köhler's procedure was appropriately modified to suit the bird's anatomy. I reported the canary's achievements in several journals ${ }^{2.4}$, one of which contains photographs ${ }^{4}$. Photographs also were published in textbooks ${ }^{5}$ and in the popular media $^{6}$.

Department of Psychology,

Nicholas PASTORE

Queens College of the City University of New York,

Flushing, New York 11367, USA

1. Epstein, R., Kirshnit, R.P., Lanza, R.P. \& Rubin, L.C. Nature 308, 61-62 (1984).

Pastore, N. J. comp. physiol. Psychol, 47, 288-289 (1954).

3. Pastore, N. Psychol. Rep. 1, 307-315 (1955).

. Pastore, N. Scient, Am, 192, $72-79$ (1955).

S. Welty, J.C. The Life of Birds, 173 (Saunders, Philadelphia 1962).

6. MD, 100-101 (March, 1960).

\section{Scientific Correspondence}

Scientific Correspondence is intended to provide a forum in which readers may raise points of a rather technical character which are not provoked by articles or letters previously published (where Matters Arising remains appropriate). 